\title{
Flexibility of the imidazolium based ionic liquids/water system for the synthesis of siliceous 10-ring containing microporous \\ frameworks
}

\author{
Inés Lezcano-González ${ }^{\mathrm{a}, \mathrm{b}}$, Matthew G. O’Brienª , Marta Počkaj ${ }^{\mathrm{c}}$, Manuel Sánchez-Sánchez ${ }^{\mathrm{d}}$, \\ Andrew M. Beale ${ }^{a, b, *}$
}

\footnotetext{
${ }^{a}$ University College London, Chemistry Department, Gordon Street, London, WC1H OAJ, UK

${ }^{b}$ Research Complex at Harwell, Rutherford Appleton Laboratory, Harwell Science and Innovation Campus, Harwell Didcot, Oxon, OX11 OFA, UK

${ }^{c}$ Faculty of Chemistry and Chemical Technology, University of Ljubljana, Večna pot 113, 1000 Ljubljana, Slovenia.

${ }^{d}$ Instituto de Catálisis y Petroleoquímica, ICP-CSIC, C/ Marie Curie, 2. 28049 Madrid, Spain
}

Email: andrew.beale@ucl.ac.uk

Tel. 0044 (0) 1235567837 


\begin{abstract}
By using asymmetric di-substituted imidazolium molecules (1-Butyl-3-methylimidazolium (BMIM) and 1-Ethyl-3-methylimidazolium (EMIM) bromide) as the structure directing agents, in combination with simple changes in silica source or sodium/water content it is possible to prepare three pure phase microporous 10-ring siliceous zeolitic structures. The crystallizations are comparatively rapid with fully crystalline material resulting in $1-3$ days at $443 \mathrm{~K}$. In contrast to many recipes reported for pure silica materials, the synthesis is performed without the use of HF or without the need to alter the properties of the SDA, while significantly lower amounts of both ionic liquid and mineralizing agent are required. The results obtained indicate that effective phase control can be achieved from a primary gel composition by minor changes to either the silica source or the water/sodium content, with a strong specificity in the formation of topologies with interconnected 10-rings.
\end{abstract}

Keywords: ionic liquid, zeolite, synthesis, imidazolium, 10-ring 


\section{Introduction}

High silica zeolites have attracted much attention for their breadth of application including catalysis, adsorption and gas separation. The synthesis of such materials is rarely straightforward since in addition to the silica source for the framework, a structure directing agent (SDA) is commonly needed to introduce the microporosity, a solvent for facilitating reactant transport, $\mathrm{OH}^{-}$or $\mathrm{F}^{-}$ions to act as mineralizers and, in some cases, alkali ions as crystallization promoters. In addition to the relative amounts of these reagents present, the synthesis of a particular microporous phase is also known to be dependent on temperature/time employed under hydrothermal reaction conditions. Perhaps the most important component for the direction of a particular microporous crystalline phase is the template or SDA. It is often envisaged to operate on a 'lock-and-key' type basis in which the kinetic diameter of the SDA closely matches that of the crystalline pore diameter in the microporous material and results in the formation of a particular crystalline phase [1-3]. But quite often the SDA simply fills the pores and in fact a number of different organic molecules can be used to prepare a specific microporous crystalline phase [2]. Zones and co-workers have demonstrated however, that high-silica phases can be readily prepared from SDA structures possessing $\mathrm{C} / \mathrm{N}$ ratios between 11-16 [3]. The efficacy of imidazolium quaternary compounds as structure directing agents for the preparation of high silica zeolites has also been recently demonstrated [4-6]. For example, a series of symmetrical imidazolium salts have been successfully employed to prepare a range of structures including SSZ-70, TON, BEA, MTW, MTT, CFI and AFX [6, 7]. Further details regarding the zeolite structures corresponding to the three letter codes can be found on the 
website for the International Zeolite Association (IZA) [8]. More recently, these compounds have also been used in pure form as combined solvent/template in what has been termed ionic liquid (IL)-based 'ionothermal synthesis' conditions to produce pure microporous aluminophosphates, layered metal phosphates, metal organic frameworks and zeolites [9-19]. Furthermore, the IL approach has also been successfully utilized as a medium for microwave transfer to crystallize purely siliceous zeolites from dried gel precursors [20]. Crucial to the formation of a microporous structure under such reaction conditions has been the presence of water as a 'co-catalyst' and/or co-SDA and with the term 'ionothermal' synthesis being coined to this effect [10, 11]. Although very little autogenous pressure is detected from these systems, water must be allowed to condense somewhere in the vessel and return to the mother liquor system since the IL looses water rapidly under typical synthesis conditions (> $373 \mathrm{~K}$ ) and without it, crystallization cannot occur.

Here we report the preparation of three pure phase 10-ring containing siliceous structures using asymmetric di-substituted imidazolium molecules (1-Butyl-3-methylimidazolium (BMIM) and 1-Ethyl-3-methylimidazolium (EMIM) bromide) as SDA under both hydrothermal and ionothermal conditions by simple tweaking of the parameters of silica source and water content. The crystallization is comparatively rapid with fully crystalline material resulting in $1-3$ days and, in contrast to many recipes reported for silica materials, is performed without HF, without the need to alter the IL by anion-exchange (i.e replacing $\mathrm{Br}^{-}$with $\mathrm{OH}^{-}$), and with significantly lower amounts of both IL and mineralizing agent $[5,6,12-16]$. Importantly, effective phase control can be achieved from a primary gel 
composition by minor changes to either the silica source or the water/sodium content, with a strong specificity in the formation of topologies with interconnected 10-rings.

\section{Experimental}

\subsection{Materials Synthesis}

Reactions were performed in $100 \mathrm{~mL}$ Teflon lined stainless steel autoclaves. Fumed silica (Cab-O-Sil M5), silica gel (Davisil 646, Sigma Aldrich), sodium silicate (Avocado, $\geq 98$ $\%$ ), sodium hydroxide (Sigma Aldrich, $\geq 98 \%$ ) and a range of imidazolium-based ionic

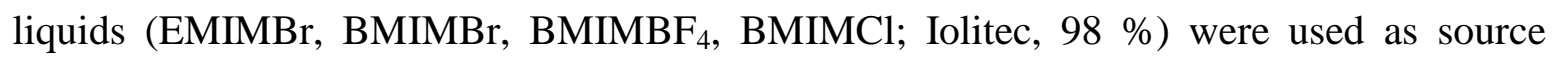
materials. The gel compositions and synthesis conditions are summarized in Table 1. In a typical synthesis, $0.15-1.5 \mathrm{~g}$ of the $\mathrm{IL}$ was added to the Teflon liner in a nitrogen glovebox along with either $1-3.77 \mathrm{~g}$ of the silica source, $0-0.1 \mathrm{~g}$ of $\mathrm{NaOH}$ and finally distilled water $(4.2-12.5 \mathrm{~g})$. In keeping with the previous work, a molar ratio of Na:Si of 0.15 was employed in order to avoid crystallization of layered structures [6]. The mixture was then left to stir in the glovebox before the vessels were sealed and placed in an oven at $443 \mathrm{~K}$ for between $1-14$ days. The products were recovered by filtration, washed with distilled water and finally oven dried at $393 \mathrm{~K}$.

\subsection{Characterization}

$\mathrm{X}$-ray diffraction (XRD) data of the samples of the as prepared samples were recorded on a

Siemens Bruker D8 machine in Bragg-Brentano geometry using a Co $\mathrm{K}_{\alpha}(1.789 \AA$ A) source 
with a rotating flat plate. The thermogravimetric analyses (TGA) were performed on crystalline samples in air (flow of air $(60 \mathrm{ml} / \mathrm{min})$ ) using a TA Instruments Q50 and heated at a rate of $10{ }^{\circ} \mathrm{C} / \mathrm{min}$ from room temperature to $900{ }^{\circ} \mathrm{C}$.

Solid-state Nuclear Magnetic Resonance (NMR) spectra were acquired at room temperature on a Bruker AV-400 spectrometer (9.4 T) using a 4-mm CP/MAS probe. ${ }^{1} \mathrm{H}$ to ${ }^{13} \mathrm{C}$ cross polarization $(\mathrm{CP})$ spectra were recorded under magic angle spinning (MAS) at $5 \mathrm{kHz}$, with a contact time of $3.5 \mathrm{~ms}$ and a recycle delay of 4 s. ${ }^{1} \mathrm{H}$ to ${ }^{29} \mathrm{Si} \mathrm{CP}-\mathrm{MAS}$ spectra were recorded with a contact time of $6 \mathrm{~ms}$ and a recycle delay of $5 \mathrm{~s}$, spinning the sample at 5 $\mathrm{kHz} .{ }^{29} \mathrm{Si}$ MAS NMR spectra were acquired with a pulse of $2.9 \mu$ s to flip the magnetization $25^{\circ}$, and a recycle delay of $60 \mathrm{~s}$, spinning the sample at $14 \mathrm{kHz}$. Both ${ }^{13} \mathrm{C}$ and ${ }^{29} \mathrm{Si}$ chemical shifts were referenced with respect to those of the primary reference tetramethylsilane (TMS) for the same nuclei.

\section{Results}

Fig. 1 contains the resultant XRD powder patterns for samples representative of the three microporous topologies prepared using the BMIMBr template, the exact conditions for the synthesis can be found in Table 1 (syntheses A1, E2 and F2). The patterns correspond to the siliceous zeolite structures TON (ZSM-22), MFI (Silicalite-1) and *MRE (ZSM-48) [8]. With the exception of ZSM-22, in which a small amount of ZSM-48 can also be seen, the samples are phase pure. The resultant ZSM-48 zeolite is known to comprise an array of 10ring pores, made up of rolled up honeycomb-like sheets of fused 6-rings and connected via 
4-rings or crankshaft chains, but is more generally described as disordered. In this case the synthetic procedure yields a pure type monoclinic form of the structure (i.e. polytypes 1, 3, 6 or 8) as opposed to an orthorhombic polytype [21]. Substituting BMIM for EMIM whilst keeping all other synthesis parameters the same (Table 1, synthesis C1) also yields the *MRE structure. However, when using EMIM as the IL and Davisil as the Si source (synthesis $\mathrm{C} 2$ ), pure phase TON is obtained.

The *MRE phase crystallises exclusively in the monoclinic form from gels containing any of the IL as SDA, irrespective of temperature, and can even crystallise at temperatures as low as $393 \mathrm{~K}$ after a relatively short synthesis time (in 10 days). The amount of crystalline product recovered under these conditions was higher when using BMIMBr. A plot detailing the extent of crystallinity of the *MRE sample - as determined using the intensity of the $015 / 033$ peak at 26.88 degrees in $2 \theta$, revealed that a small amount of crystalline product had been formed after $24 \mathrm{~h}$ (remainder determined to be amorphous), suggestive of a short induction period prompted by a rather concentrated synthesis gel (see Fig. 1d). After $48 \mathrm{~h}$ the amount of crystalline material increases, whereas between 48 and $72 \mathrm{~h}$ a two-fold increase in the peak intensity is seen. Little change is observed between 72 and $120 \mathrm{~h}$ suggesting the end of crystallization. A change in the peak full width at half maximum (FWHM) as a function of time demonstrates that in addition to more crystalline product being formed, the particle size increases reaching a maximum of around $100 \mathrm{~nm}$ (as determined by the Scherrer method).

\subsection{Synthesis variables}


Table 1 summarizes a series of experiments selected to clarify the effect of different synthesis parameters on the final product. Crucial parameters affecting phase selectivity appear to be silica source, $\mathrm{H}_{2} \mathrm{O}$ :IL ratio and the amount of mineralizer (hydroxide). Crystallization temperature/time (Table 1, syntheses A1-3) and cation of the IL (synthesis C1) affect the degree of crystallinity of the final product (data not given) although not the topology of the crystalline phase. A reduction in the amount of $\mathrm{NaOH}$ in turn, inhibits the formation of crystalline products (syntheses B1-2). Substituting the $\mathrm{Br}^{-}$anion of the IL by $\mathrm{Cl}^{-}$leads to the crystallization of phase-pure *MRE (though using an increased concentration of IL), whereas switching to a more hydrophobic IL due to the presence of $\mathrm{BF}_{4}{ }^{-}$anions sees a failure of any microporous crystalline phase to form (syntheses D1-2). The inefficacy of $\mathrm{BMIMBF}_{4}$ as $\mathrm{SDA}$ has been previously explained as a result of the nanostructural organization of the $\mathrm{IL} / \mathrm{H}_{2} \mathrm{O}$ mixtures; i.e. the low energy of interaction between the $\mathrm{BF}_{4}{ }^{-}$anion and water appears to be unable to induce a stable template structure within the synthesis media [22]. In contrast, a robust synthesis composition allows the formation of the *MRE phase with either BMIM or EMIM (syntheses A1 and C1).

Interestingly, reduction of the water content (synthesis E1) leads to co-crystallization of the TON phase, possessing a lower framework density (FD) (FD of TON is $18.1 \mathrm{~T} / 1000 \AA^{3}$, while FD of *MRE is $19.7 \mathrm{~T} / 1000 \AA^{3}$ ). The same effect is observed when increasing the $\mathrm{IL} / \mathrm{H}_{2} \mathrm{O}$ ratio (synthesis $\mathrm{E} 4$ ) resulting in the formation of a partially crystallized TON phase. More TON than ${ }^{*}$ MRE is observed after $48 \mathrm{~h}$ (synthesis E2) than at $24 \mathrm{~h}$ (synthesis E1), suggestive of a slower rate of crystallization. 
Switching the Si source has a large effect on the final crystalline product. Liquid sources such as TEOS and Ludox only yield amorphous products (data not shown). Cab-O-Sil or Davisil (loosely powdered sources) yield *MRE and TON, respectively, with phase pure TON formed from a combination of Davisil and EMIM (syntheses C1-2). Swapping the Si source to Sodium silicate (syntheses F1-2 and F4) exclusively yields the MFI structure. Note that in this case, $\mathrm{NaOH}$ was not added since both $\mathrm{Na}^{+}$and $\mathrm{OH}^{-}$ions (resulting from the corresponding hydrolysis) are already given by the Si source. In the latter case, changing the amount of the other synthetic components restricts the formation of the MFI phase and does not yield additional crystalline products. These results are not completely unexpected as the Si sources employed differ in reactivity and solubility. While ethanol released during the hydrolysis of TEOS may result in a different synthesis media and affect the zeolite crystallization, the use of sodium silicate increases the $\mathrm{Na}_{2} \mathrm{O} / \mathrm{SiO}_{2}$ molar ratio from the 'standard' 0.075 to 1 , influencing the crystallization time and hence, the obtained product. In fact, although we cannot readily exclude a co-templating effect from $\mathrm{Na}^{+}$, the results obtained show that $\mathrm{Na}^{+}$(or else the particular complexes formed by the IL and the components in the synthesis gel) may have a critical role in the formation of the MFI structure. Addition of Cab-O-Sil or Davisil, presenting different surface areas (Davisil 646: $300 \mathrm{~m}^{2} / \mathrm{g}$; Cab-O-Sil M5: $200 \mathrm{~m}^{2} / \mathrm{g}$ ), appears to have an effect in the nucleation rate and thus, in crystallization and final phase, as high surface area Si sources present a better solubility in basic media.

Attempts to introduce aluminum into the synthesis/final crystalline product proved unsuccessful (data not shown); an amorphous product resulting even after a reaction time of 
14 days. This is consistent with previous works which showed that the incorporation of $\mathrm{Al}$ into the *MRE framework is complicated, reporting the synthesis of pure, Al-containing ZSM-48 zeolites only when the $\mathrm{SiO}_{2} / \mathrm{Al}_{2} \mathrm{O}_{3}$ in the synthesis mixture was above 400 , even with the addition of seeds [23, 24].

\subsection{Solid-state NMR characterization}

Fig. 2 shows the ${ }^{1} \mathrm{H}$ to ${ }^{13} \mathrm{C} \mathrm{CP}-\mathrm{NMR}$ spectra of as-prepared, representative samples with topologies TON, MFI and *MRE, prepared using BMIMBr as SDA. All the spectra are characterized by the presence of relatively broad resonances, close to those detected for the IL in solution $\left(125 \mathrm{MHz}, \mathrm{CD}_{2} \mathrm{Cl}_{2}\right): \delta 136.2,123.8,122.5,49.7,36.1,31.9,19.3$ and 13.1 ppm, and consistent with the incorporation of fully intact BMIM cations within all three framework structure types. The precise assignments of these signals to the different ${ }^{13} \mathrm{C}$ environments found in a BMIMBr molecule are indicated in Fig.2.

As seen in Fig. 3, the ${ }^{29} \mathrm{Si}$ MAS NMR ${ }^{1} \mathrm{H}$ to ${ }^{29} \mathrm{Si}$ CP MAS NMR spectra of the samples present two broad resonances, which can be readily ascribed to the presence of $\mathrm{Q}^{4}$ ( $\mathrm{Si}(\mathrm{O}-$ $\left.\mathrm{Si}_{4}\right)$ and $\mathrm{Q}^{3}\left(\mathrm{Si}(\mathrm{O}-\mathrm{Si})_{3} \mathrm{OH}\right)$ environments [25]. The relative intensity of the $\mathrm{Q}^{3}$ signals is higher in the $\mathrm{CP}$ spectra, as expected from the proximity of $-\mathrm{OH}$ linked to these $\mathrm{Si}$ atoms. Since the samples are entirely siliceous, the presence of $\mathrm{Q}^{3}$ species is most probably due to the effect of the small particle size of the resultant crystallites as well as the presence of internal defects close to where the BMIM cations locate [26, 27]. Owing to the presence of these defects, it is not possible to distinguish between different crystallographic sites in the $\mathrm{Q}^{4}$ region, and only a certain asymmetry is observed for the $\mathrm{Q}^{4}$ resonance, especially in the 
spectrum of the MFI sample. The $\mathrm{Q}^{3} / \mathrm{Q}^{4}$ intensity ratio was calculated from the single-pulse

${ }^{29}$ Si MAS NMR spectra, which can be considered strictly quantitative. This ratio was of 0.25, 0.17 and 0.21 for TON, MFI and ${ }^{*}$ MRE materials, respectively. It is remarkable that a significant presence of the $\mathrm{Q}^{3}$ environments is also found in IL-based, pure-silica MFI and TON zeolites, even when fluoride is used as mineralizer [28], in contrast to the role of fluoride with respect to that of $\mathrm{OH}^{-}$when using conventional ammonium-based SDAs [29, 30].

\subsection{Thermogravimetric characterization}

To quantify the amount of BMIM cations incorporated into the microporous system, we also characterized our samples by thermogravimetric analyses (TGA). As seen in Fig. 4, the TGA data for the three zeolite samples as a function of temperature show two different regions; the weight loss below $523 \mathrm{~K}$ corresponds to the desorption of water, and that between 523 and $1173 \mathrm{~K}$ corresponds to the decomposition of the IL. For ${ }^{*} \mathrm{MRE}$, the observed loss of BMIM (4.7 \%) indicates a unit cell composition of $\left[\mathrm{Si}_{48} \mathrm{O}_{96}\right]\left(\mathrm{C}_{8} \mathrm{~N}_{2} \mathrm{H}_{15}\right)$, while for MFI $(8.9 \%)$ corresponds to a composition of $\left[\mathrm{Si}_{96} \mathrm{O}_{192}\right]\left(\mathrm{C}_{8} \mathrm{~N}_{2} \mathrm{H}_{15}\right)_{4}$. In both cases, the BMIM occupancy is lower than that previously reported when using hexanediamine, and could be perhaps suggestive of a different arrangement of the SDA [31]. Note however that, on the basis of similar results obtained for ZSM-22 zeolite, it has been inferred that for pure siliceous zeolites a specific molar ratio may not be necessary, as no charge-balancing is required [32]. Additionally, the high temperature required for the decomposition of the IL for *MRE, in contrast to the abrupt weight loss observed for MFI, could be suggestive 
of diffusion limitations, possibly related to a partial blockage of the one-dimensional channels as a result of a disordered zeolite structure.

The organic mass loss obtained for TON $(8.4 \%)$ corresponds to a unit cell composition of $\left[\mathrm{Si}_{24} \mathrm{O}_{48}\right]\left(\mathrm{C}_{8} \mathrm{~N}_{2} \mathrm{H}_{15}\right)$, indicating - in line with previous works, that more BMIM cations fill the void volume of the zeolite [14]. Considering that ${ }^{*}$ MRE and TON are one-dimensional zeolites it is likely that BMIM/EMIM cations locate in the 10-ring channels in all of the zeolites studied. In the case of MFI, single crystal data has revealed that BMIM cations are sufficiently ordered so as to be observable by diffraction, with two BMIM cations located in the straight 10-ring channel - in good agreement with the above results [12].

\section{Discussion}

Ionic liquids have attracted recent attention as structure directing agents in the formation of microporous materials owing to their solvent properties, low vapor pressure and thermal stability, and evidence has been provided about their structure directing effect on the synthesis of a number of topologies. Critically most work has focused on the application of ILs based on imidazolium cations, but to date there appears very little correspondence with the formation of a particular family of porous materials. Our results demonstrate that actually parameters such as the Si source, ionic liquid:water ratio, the presence and nature of the mineralizer and time play a key role in the nature and crystallinity of the final product. This control through synthesis conditions, which in principle are not directly related with the final topology, suggests that the strictly speaking template role of the IL is rather reduced, although much stronger than in $\mathrm{AlPO}_{4}$-based materials. Perhaps most 
interesting is the observation that from a core reactant composition of $\mathrm{SiO}_{2}:$ 0.047-0.078 IL: 0.075-1 $\mathrm{Na}_{2} \mathrm{O}$ : 18.2-41.7 $\mathrm{H}_{2} \mathrm{O}$ all three purely siliceous forms of TON, MRE and MFI structures can be afforded; only minor changes to either the Si source (Cab-O-Sil, Davisil or Sodium silicate) or else water/sodium content are needed to effect phase control. Specifically a lowering of the $\mathrm{Si}: \mathrm{H}_{2} \mathrm{O}$ ratio (implicit $\mathrm{IL}: \mathrm{H}_{2} \mathrm{O}$ ratio) sees a preferential formation of TON over "MRE, whereas the use of sodium silicate solution as Si source leads to the formation of MFI. The formation of structures possessing 10-rings as the largest structural ring, over smaller or larger ring containing systems appears related to a high stabilization energy. However, if high stabilization energy is the important parameter in phase formation one might also expect to see also the 12-ring containing (BEA) phase, but this was not seen in any of the synthesis attempts performed here [13]. The conditions for the preparation of the MTW phase in high silica form may be however very specific [6, 33]. Whereas failure to observe ZSM-23 (MTT) phase might be related to the difficulty in preparing this phase in a pure silica form without HF [34]. It is however difficult to fully rationalize the preferential formation of the 3D MFI structure over the 1D TON and "MRE although the combination of a difference in Si source and $\mathrm{Na}^{+} / \mathrm{OH}^{-}$content in the reactant solution is likely to result in a difference in speciation (either simple solution based species or critical nuclei) which appears then important for subsequent microporous material formation.

\section{Summary and Conclusions}


Using asymmetrical imidazolium quaternary compounds EMIM and BMIM as structure directing agents in combination with a variable silica source and varying extent of water/sodium addition, it has been possible to identify conditions for the preparation of three pure siliceous, 10-ring microporous frameworks ("MRE, TON and MFI). Importantly, the synthesis of these materials using the methods reported here is more facile than the more common methods used in their preparation since they require the use of one silica source, do not use HF, or do not require the exchange of the IL. Moreover, lower amounts of both IL and mineralizing agent are required. The preferential formation of these 10-ring containing porous materials suggests a structure directing effect of the asymmetrical imidazolium quaternary cation at least on a local scale; but the final 3D arrangement of atoms in the final crystalline structure appears also to be influenced (and more importantly, controlled) by synthesis conditions.

It would seem likely that if the three phases ("MRE, TON and MFI) can be prepared in this manner, then structurally similar phases MTT and MEL and possibly STF/SFF could also be synthesizable within the compositional space available. Preparation of isomorphously substituted frameworks also does not appear facile although has not yet been fully explored. Both aspects may however be realized if $\mathrm{HF}$ were also to be used in the synthesis approach $[30,35]$.

\section{Acknowledgements}


NWO-CW and EPSRC (EP/K007467/1) is thanked for funding support to Andrew M.

Beale and I. Lezcano-Gonzalez respectively. Marjan Versluijs-Helder (Utrecht University, the Netherlands) is thanked for performing the TGA measurements. Slovenian research agency is acknowledged for financial support (grant MR-29397).

\section{References}

[1] C.S. Cundy, P.A. Cox, Microporous Mesoporous Mater., 82 (2005) 1-78.

[2] M. Davis, R. Lobo, Chem. Mater., 4 (1992) 756-768.

[3] S.I. Zones, Y. Nakagawa, G.S. Lee, C.Y. Chen, L.T. Yuen, Microporous Mesoporous Mater., 21 (1998) 199-211.

[4] X. Sun, J. King, J.L. Anthony, Chem. Eng. J., 147 (2009) 2-5.

[5] R.H. Archer, S.I. Zones, M.E. Davis, Microporous Mesoporous Mater., 130 (2010) 255265.

[6] S.I. Zones, A.W. Burton, J. Mater. Chem., 15 (2005) 4215-4223.

[7] R.H. Archer, J.R. Carpenter, S.J. Hwang, A.W. Burton, C.Y. Chen, S.I. Zones, M.E. Davis, Chem. Mat., 22 (2010) 2563-2572.

[8] http://www.iza-structure.org/databases/.

[9] D.S. Wragg, B. Le Ouay, A.M. Beale, M.G. O'Brien, A.M.Z. Slawin, J.E. Warren, T.J.

Prior, R.E. Morris, J. Solid State Chem., 183 (2010) 1625-1631.

[10] E.R. Parnham, R.E. Morris, Acc. Chem. Res., 40 (2007) 1005-1013.

[11] E.R. Cooper, C.D. Andrews, P.S. Wheatley, P.B. Webb, P. Wormald, R.E. Morris, Nature, 430 (2004) 1012-1016.

[12] P.S. Wheatley, P.K. Allan, S.J. Teat, S.E. Ashbrook, R.E. Morris, Chem. Sci., 1 (2010) 483-487.

[13] J. Martinez Blanes, J. Martínez Blanes, B. Szyja, F. Romero Sarria, M. Centeno, E.J.M. Hensen, J. Odriozola, S. Ivanova, Chem. Eur. J., 19 (2013) 2122-2130.

[14] H. Wen, Y. Zhou, J. Xie, Z. Long, W. Zhang, J. Wang, RSC Adv., 4 (2014) 4964749654.

[15] Y. Tian, M. McPherson, P. Wheatley, R. Morris, Z. Anorg. Allg. Chem. (1950), 640 (2014) 1177-1181.

[16] D. Yuan, D. He, Z. Song, M. Zhang, Y. Wei, Y. He, S. Xu, Z. Liu, Y. Xu, Microporous Mesoporous Mater., 204 (2015) 1-7.

[17] Z. Lin, D.S. Wragg, J.E. Warren, R.E. Morris, J. Am. Chem. Soc., 129 (2007) 1033410335 .

[18] Z. Lin, A.M.Z. Slawin, R.E. Morris, J. Am. Chem. Soc., 129 (2007) 4880-4881.

[19] D.S. Wragg, A.M.Z. Slawin, R.E. Morris, Solid State Sci., 11 (2009) 411-416.

[20] R. Cai, Y. Liu, S. Gu, Y.S. Yan, J. Am. Chem. Soc., 132 (2010) 12776-12777.

[21] R. Lobo, H. van Koningsveld, J. Am. Chem. Soc., 124 (2002) 13222-13230. 
[22] R. Ayala, S. Ivanova, J.M.M. Blanes, F. Romero Sarria, J. Odriozola, J. Phys. Chem. B, 118 (2014) 3650-3660.

[23] K. Suzuki, T. Hayakawa, Microporous Mesoporous Mater., 77 (2005) 131-137.

[24] G. Zhao, J. Teng, Y. Zhang, Z. Xie, Y. Yue, Q. Chen, Y. Tang, Appl. Catal. A, 299 (2006) 167-174.

[25] S. Axon, J. Klinowski, Appl. Catal. A, 81 (1992) 27-34.

[26] D.H. Olson, W.O. Haag, W.S. Borghard, Microporous Mesoporous Mater., 35-6 (2000) 435-446.

[27] M. Kasunic, J. Legisa, A. Meden, N.Z. Logar, A.M. Beale, A. Golobic, Microporous Mesoporous Mater., 122 (2009) 255-263.

[28] A. Rojas, L. Gómez Hortigüela, M. Camblor, J. Am. Chem. Soc., 134 (2012) 38453856.

[29] H. Koller, R. Lobo, S. Burkett, M. Davis, J. Phys. Chem., 99 (1995) 12588-12596.

[30] M.A. Camblor, L.A. Villaescusa, M.J. Diaz-Cabanas, Top. Catal., 9 (1999) 59-76.

[31] S. Burkett, M. Davis, Chem. Mater., 7 (1995) 1453-1463.

[32] J. Williams, Z.A.D. Lethbridge, G. Clarkson, S. Ashbrook, K. Evans, R. Walton, Microporous Mesoporous Mater., 119 (2009) 259-266.

[33] A. Mitra, C.W. Kirby, Z.B. Wang, L.M. Huang, H.T. Wang, Y.N. Huang, Y.S. Yan, Microporous Mesoporous Mater., 54 (2002) 175-186.

[34] S.I. Zones, R.J. Darton, R. Morris, S.J. Hwang, J. Phys. Chem. B, 109 (2005) 652-661. [35] P. Wagner, S.I. Zones, M.E. Davis, R.C. Medrud, Angew. Chem. Int. Ed., 38 (1999) 1269-1272. 


\section{Tables}

Table 1. Synthesis parameters employed for the preparation of siliceous zeolites under hydrothermal conditions.

\begin{tabular}{|c|c|c|c|c|c|c|c|c|c|c|}
\hline \multirow[t]{2}{*}{ Synthesis } & \multirow{2}{*}{$\begin{array}{c}\text { Varied } \\
\text { parameters }\end{array}$} & \multirow[t]{2}{*}{$\mathbf{I L}^{\mathrm{a}}$} & \multirow[t]{2}{*}{ Si source } & \multicolumn{3}{|c|}{$\begin{array}{c}\text { Molar composition } \\
\mathrm{SiO}_{2}: x \mathrm{IL}: y \mathrm{Na}_{2} \mathrm{O}: z \mathrm{H}_{2} \mathrm{O}\end{array}$} & \multicolumn{2}{|c|}{$\begin{array}{c}\text { Hydrothermal } \\
\text { treatment }\end{array}$} & \multicolumn{2}{|c|}{$\begin{array}{c}\text { Crystalline } \\
\text { phase }\end{array}$} \\
\hline & & & & $x$ & $y$ & $z$ & $\mathbf{T}(\mathbf{K})$ & $\mathbf{t}(\mathbf{h})$ & Main & $2^{\text {nd }}$ \\
\hline A1 & \multirow{3}{*}{$\begin{array}{c}\text { Hydrothermal } \\
\text { treatment }\end{array}$} & $\mathrm{B} \mathrm{Br}$ & Cab-O-Sil & 0.047 & 0.075 & 41.7 & 443 & 48 & MRE & - \\
\hline $\mathrm{A} 2$ & & $\mathrm{~B} \mathrm{Br}$ & Cab-O-Sil & 0.047 & 0.075 & 41.7 & 443 & 120 & MRE & - \\
\hline $\mathrm{A} 3$ & & $\mathrm{~B} \mathrm{Br}$ & Cab-O-Sil & 0.047 & 0.075 & 41.7 & 393 & 240 & MRE & - \\
\hline B1 & \multirow{2}{*}{$\begin{array}{l}\mathrm{NaOH} \\
\text { content }\end{array}$} & $\mathrm{B} \mathrm{Br}$ & Cab-O-Sil & 0.047 & - & 41.7 & 443 & 48 & $\mathrm{Am}^{\mathrm{b}}$ & - \\
\hline B2 & & $\mathrm{B} \mathrm{Br}$ & Cab-O-Sil & 0.047 & 0.038 & 41.7 & 443 & 48 & $\mathrm{Am}$ & - \\
\hline $\mathrm{C} 1$ & \multirow{2}{*}{$\begin{array}{c}\mathrm{Si} \\
\text { source }\end{array}$} & $\mathrm{E} \mathrm{Br}$ & Cab-O-Sil & 0.047 & 0.075 & 41.7 & 443 & 48 & MRE & - \\
\hline $\mathrm{C} 2$ & & $\mathrm{E} \mathrm{Br}$ & Davisil & 0.047 & 0.075 & 41.7 & 443 & 48 & TON & - \\
\hline D1 & \multirow{2}{*}{$\begin{array}{c}\mathrm{IL} \\
\text { anion }\end{array}$} & $\mathrm{B} \mathrm{Cl}$ & Cab-O-Sil & 0.516 & 0.075 & 41.7 & 443 & 48 & MRE & - \\
\hline D2 & & $\mathrm{B} \mathrm{BF}_{4}$ & Cab-O-Sil & 0.399 & 0.075 & 41.7 & 443 & 48 & $\mathrm{Am}$ & - \\
\hline E1 & \multirow{4}{*}{$\begin{array}{l}\mathrm{H}_{2} \mathrm{O} \text { content } \\
\text { Cryst. time } \\
\text { Si source } \\
\text { IL content }\end{array}$} & $\mathrm{B} \mathrm{Br}$ & Cab-O-Sil & 0.041 & 0.075 & 20.9 & 443 & 24 & MRE & TON \\
\hline E2 & & $\mathrm{B} \mathrm{Br}$ & Cab-O-Sil & 0.041 & 0.075 & 20.9 & 443 & 48 & TON & MRE \\
\hline E3 & & $\mathrm{B} \mathrm{Br}$ & Davisil & 0.041 & 0.075 & 21.7 & 443 & 48 & TON & Try $^{\mathrm{c}}$ \\
\hline E4 & & $\mathrm{B} \mathrm{Br}$ & Cab-O-Sil & 0.411 & 0.075 & 14.0 & 443 & 24 & TON & $\mathrm{Am}$ \\
\hline F1 & \multirow{4}{*}{$\begin{array}{c}\mathrm{H}_{2} \mathrm{O} \text { content/ } \\
\text { Si source } \\
\mathrm{H}_{2} \mathrm{O} \text { content } \\
\text { IL content }\end{array}$} & $\mathrm{B} \mathrm{Br}$ & Na silicate & 0.078 & 1.000 & 18.2 & 443 & 24 & MFI & - \\
\hline $\mathrm{F} 2$ & & $\mathrm{~B} \mathrm{Br}$ & Na silicate & 0.078 & 1.000 & 18.2 & 443 & 48 & MFI & - \\
\hline F3 & & $\mathrm{B} \mathrm{Br}$ & Na silicate & 0.078 & 1.000 & 9.2 & 443 & 24 & Am. & - \\
\hline F4 & & $\mathrm{B} \mathrm{Br}$ & Na silicate & 0.025 & 1.000 & 18.2 & 443 & 48 & MFI & - \\
\hline
\end{tabular}

${ }^{a} I L$ cation: $B=$ BMIM; $E=$ EMIM $;{ }^{b} A m=$ Amorphous $;{ }^{c}$ Try $=$ Tridymite 


\section{Figure captions}

Fig. 1. XRD patterns of as-prepared a) ZSM-22 (TON), b) Silicalite-1 (MFI) and c) ZSM48 ( $^{*} \mathrm{MRE}$ ) after $48 \mathrm{~h}$ at $443 \mathrm{~K}$ using BMIMBr as the SDA (Table 1, syntheses E2, F2 and A1). Indexing lines for the crystalline phases obtained from the IZA database have been added to confirm the presence of phase pure material. An asterisk in a) highlights the presence of a small amount of ${ }^{*}$ MRE in the sample. In d) is shown a typical growth curve (determined using the intensity of the $015 / 033$ peak at 26.88 degrees in $2 \theta$ ) for ZSM-48, illustrating a plateau in crystallite growth after $70 \mathrm{~h}$ of reaction.

Fig. 2. ${ }^{1} \mathrm{H}$ to ${ }^{13} \mathrm{C} \mathrm{CP}$ MAS NMR spectra recorded on as-prepared siliceous zeolites synthesized using BMIM. The identification of 8 resonances at $\delta 136.2,123.8,122.5,49.7$, 36.1, 31.9, 19.3 and $13.1 \mathrm{ppm}$ illustrates that the starting cation remains intact after synthesis.

Fig. 3. ${ }^{29} \mathrm{Si}$ MAS NMR (left) and ${ }^{1} \mathrm{H}$ to ${ }^{29} \mathrm{Si}$ CP MAS NMR spectra (right) recorded on assynthesized zeolite samples. Two resonances at c.a. $\delta-102$ and -113 ppm due to $\mathrm{Q}^{3}$ and $\mathrm{Q}^{4}$ sites can be respectively identified in the spectra of all three zeolite samples.

Fig. 4. TGA mass loss for all three samples heated in air at $10 \mathrm{~K} / \mathrm{min}$. to $1173 \mathrm{~K}$. The mass loss curves correspond to *MRE (dotted line), TON (thick line) and MFI (dashed lined). 
The total mass loss corresponds to $4.7 \%$ ("MRE), $8.4 \%$ (TON) and $8.9 \%$ (MFI) respectively.

Figures

a)

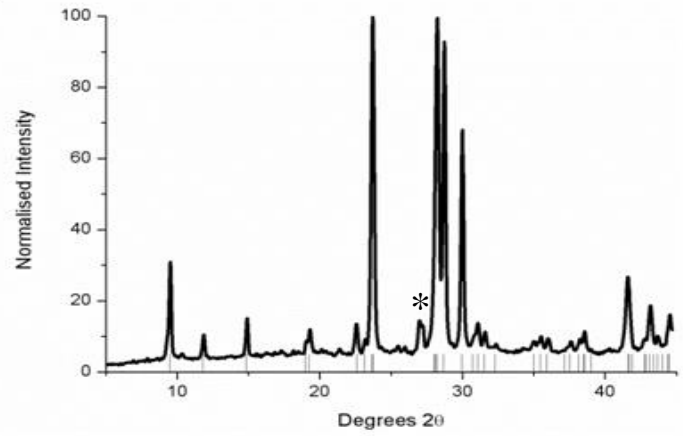

c)

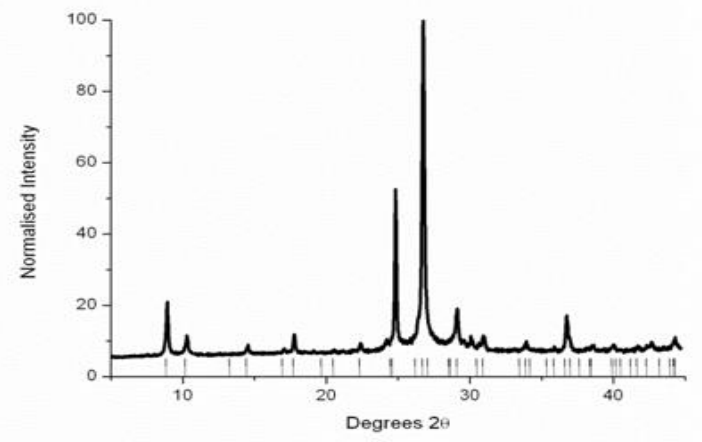

b)

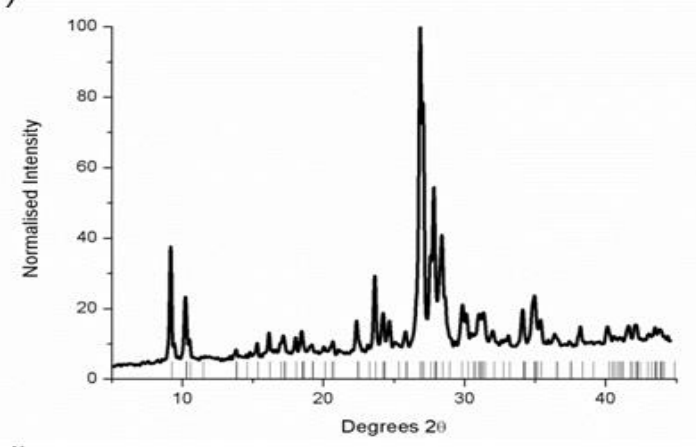

d)

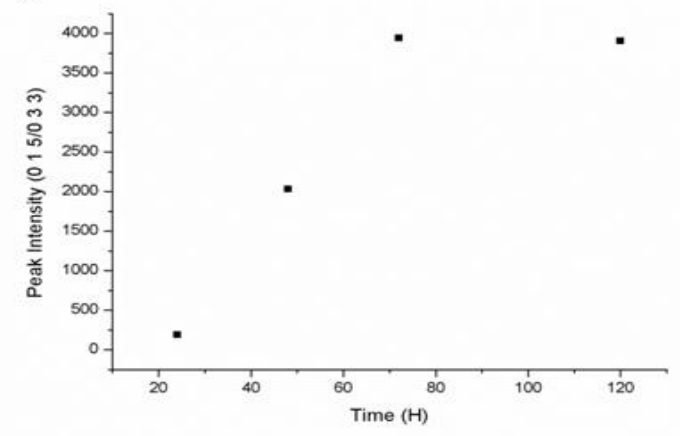

Figure 1 


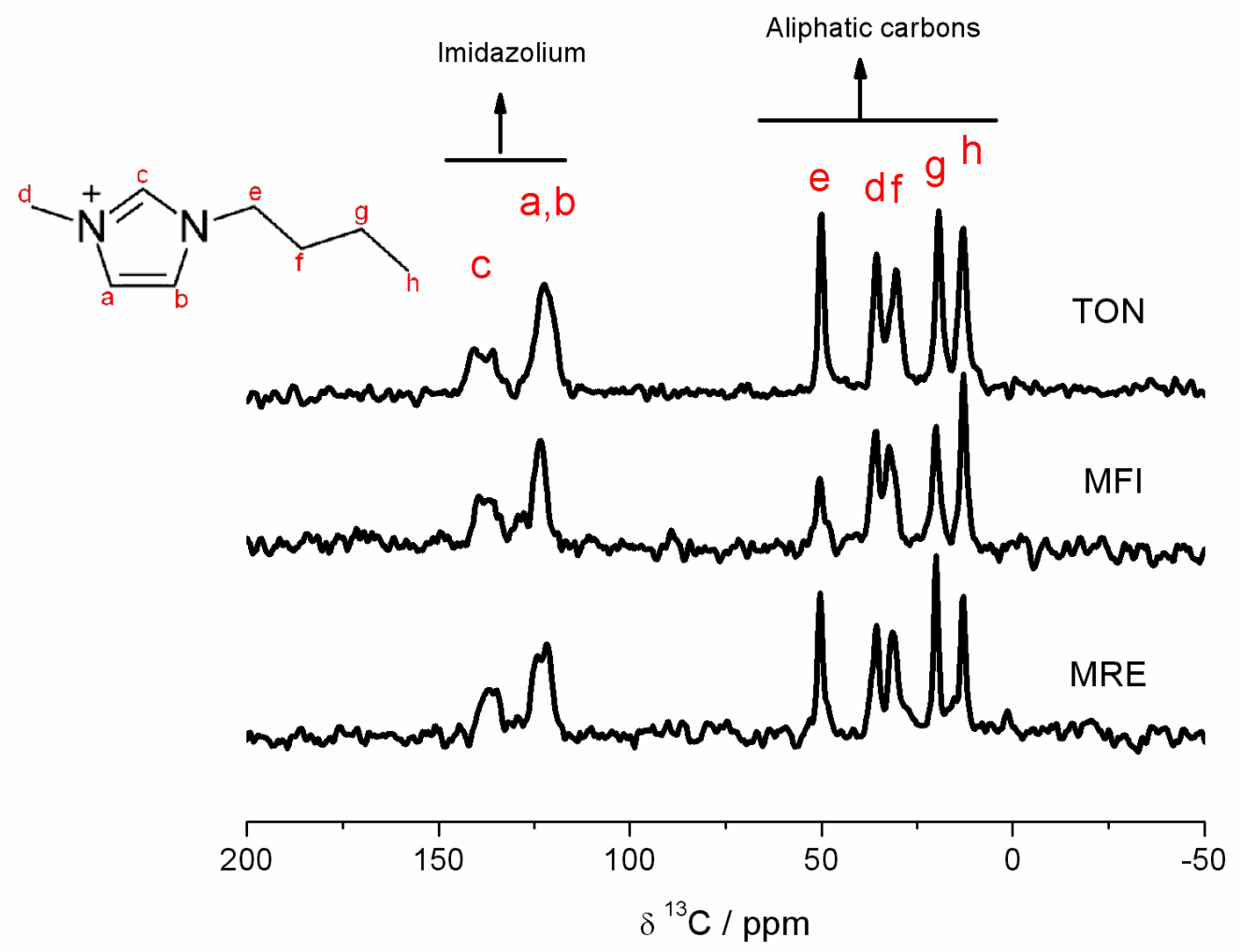

Figure 2. 


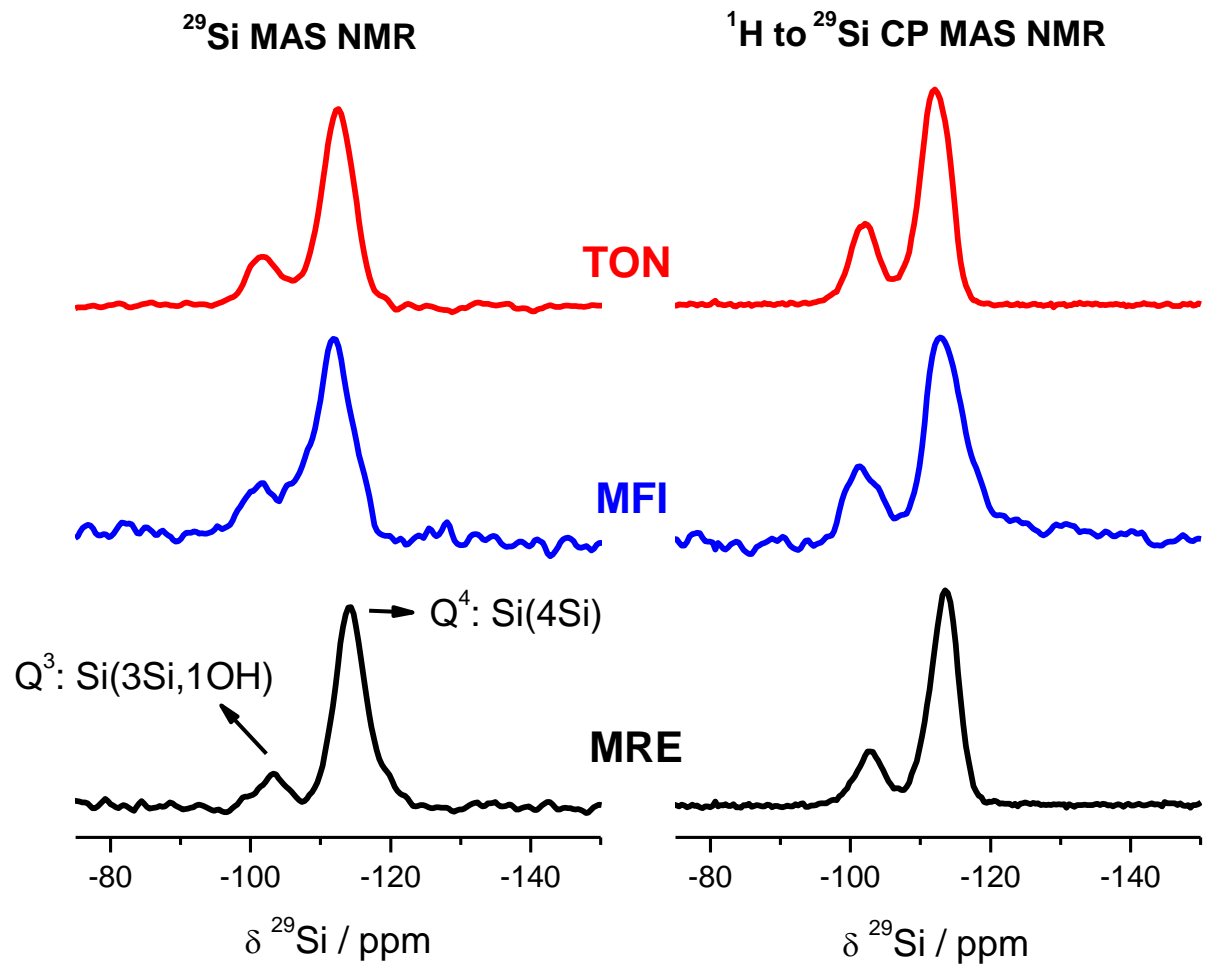

Figure 3. 


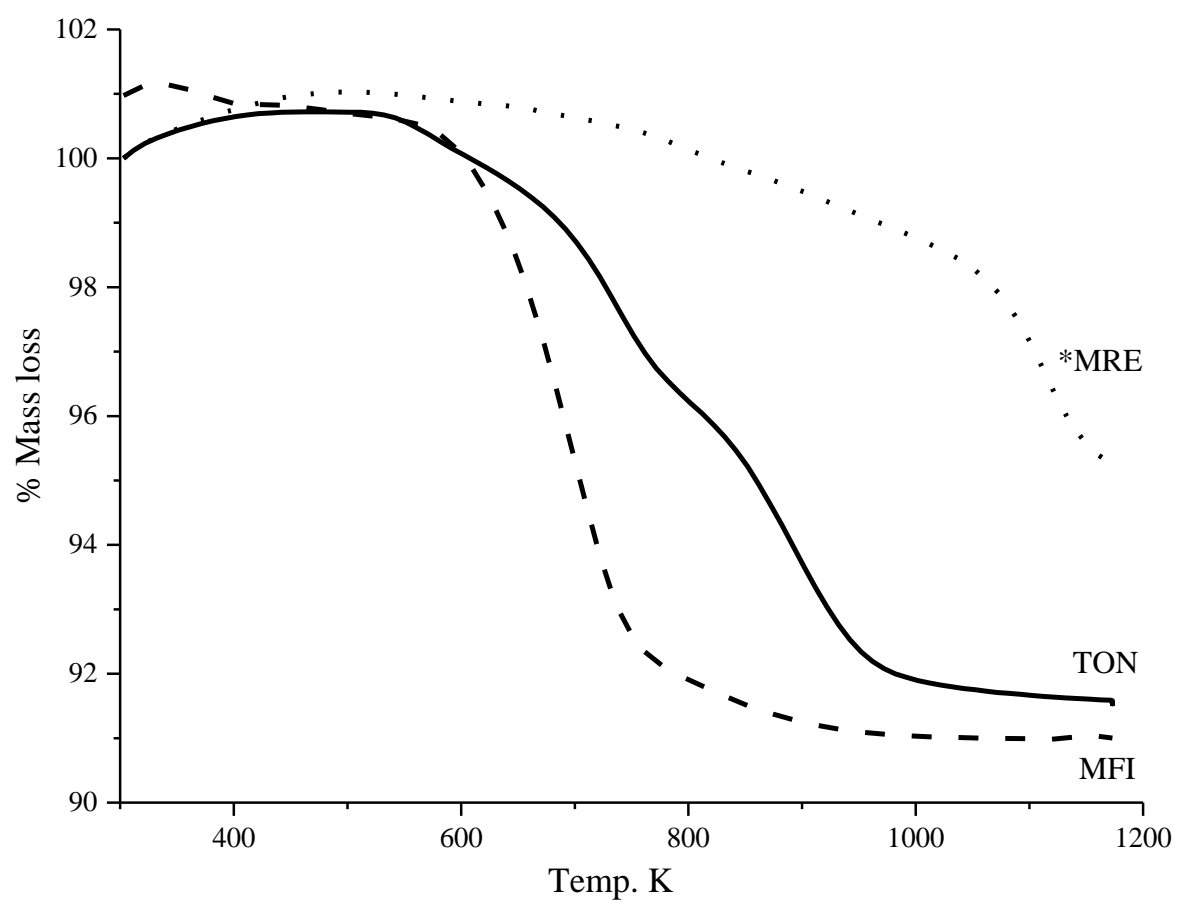

Figure 4. 